\title{
Escherichia coli O157:H7 infections associated with contaminated pork products - Alberta, Canada, July-October 2014
}

\author{
L Honish ${ }^{1,2^{*}}$, N Punja ${ }^{1,2}$, S Nunn ${ }^{1,2}$, D Nelson ${ }^{1,2}$, N Hislop ${ }^{1,2}$, G Gosselin ${ }^{1,2}$, N Stashko ${ }^{2,3}$, D Dittrich ${ }^{2,3}$
}

\section{Summary}

\section{What is already known about this topic?}

Pork is a known, although infrequent, source of human Escherichia coli O157:H7 infection. E. coli O157:H7 infections often result in clinically severe illness with serious complications in humans.

\section{What is added by this report?}

During July-October 2014, an outbreak of 119 cases of E. coli O157:H7 infections associated with exposure to contaminated pork products occurred in Alberta, Canada. E. coli O157:H7contaminated pork and pork production environments and mishandling of pork products were identified at all key points in the implicated pork distribution chain. Measures to control the outbreak included product recalls, destruction of pork products, temporary food facility closures, targeted interventions to mitigate improper pork-handling practices, and prosecution of a food facility operator.

\section{What are the implications for public health practice?}

Pork should be considered in public health E. coli O157:H7 investigations and prevention messaging, and pork handling and cooking practices should be carefully assessed during regulatory food facility inspections.

\author{
Affiliations \\ ${ }^{1}$ Alberta Health Services, Canada \\ 2 Investigative Team from \\ Alberta Health Services, Alberta \\ Provincial Laboratory for Public \\ Health, Alberta Health, Alberta \\ Agriculture and Forestry, Public \\ Health Agency of Canada, \\ Canadian Food Inspection \\ Agency, Health Canada, First \\ Nations and Inuit Health Branch \\ ${ }^{3}$ Alberta Agriculture and Forestry, \\ Canada \\ † This paper is identical in \\ content to the primary article \\ published in the Morbidity and \\ Mortality Weekly Report (MMWR) \\ and released electronically on \\ January 5, 2017, having met \\ the guidelines for simultaneous \\ publication as set forth by the \\ International Committee of \\ Medical Journal Editors (www. \\ icmje.org) \\ *Correspondence: lance.honish@ \\ ahs.ca
}

Suggested citation: Honish L, Punja N, Nunn S, Nelson D, Hislop N, Gosselin G, Stashko N, Dittrich D. Escherichia coli O157:H7 infections associated with contaminated pork products - Alberta, Canada, July-October 2014. Can Commun Dis Rep. 2017;43(1):21-4. https://doi.org/10.14745/ccdr.v43i01a04

\section{Introduction}

During July-October 2014, an outbreak of 119 Escherichia coli O157:H7 infections in Alberta, Canada was identified through notifiable disease surveillance and investigated by local, provincial, and federal public health and food regulatory agencies. Twenty-three (19\%) patients were hospitalized, six of whom developed hemolytic uremic syndrome; no deaths were reported. Informed by case interviews, seven potential food sources were identified and investigated. The majority of patients reported having consumed meals containing pork at Asian-style restaurants in multiple geographically diverse Alberta cities during their exposure period. Traceback investigations revealed a complex pork production and distribution chain entirely within Alberta. E. coli O157:H7-contaminated pork and pork production environments and mishandling of pork products were identified at all key points in the chain, including slaughter, processor, retail, and restaurant facilities. An outbreak-specific pulsed-field gel electrophoresis (PFGE) cluster pattern was found in clinical and pork E. coli O157:H7 isolates. Measures to mitigate the risk for exposure and illness included pork product recalls, destruction of pork products, temporary food facility closures, targeted interventions to mitigate improper pork-handling practices identified at implicated food facilities, and prosecution of a food facility operator. Pork should be considered a potential source in E. coli O157:H7 investigations and prevention messaging, and pork handling and cooking practices should be carefully assessed during regulatory food facility inspections.

\section{Epidemiologic Investigation}

For this outbreak, a case was defined as a laboratory culture-confirmed E. coli O157:H7 infection with one of 16 PFGE cluster patterns identified in a resident of or visitor to Canada during July-October 2014. Cases were identified through notifiable disease surveillance. 
A total of 119 outbreak cases were identified, including four $(3 \%)$ in patients who were classified as having secondary infections (i.e., acquired through household contact with an outbreak-associated patient). All patients were in Alberta during all or part of the incubation period. Dates of illness onsets for the 119 patients ranged from July 20 to October 6 (Figure 1). Cases occurred among persons in a wide geographic distribution across Alberta. Twenty-three (19\%) patients were hospitalized,

Figure 1: Cases of pork-associated E. coli O157:H7 infection week of onset and region - Alberta, Canada, July-October 2014

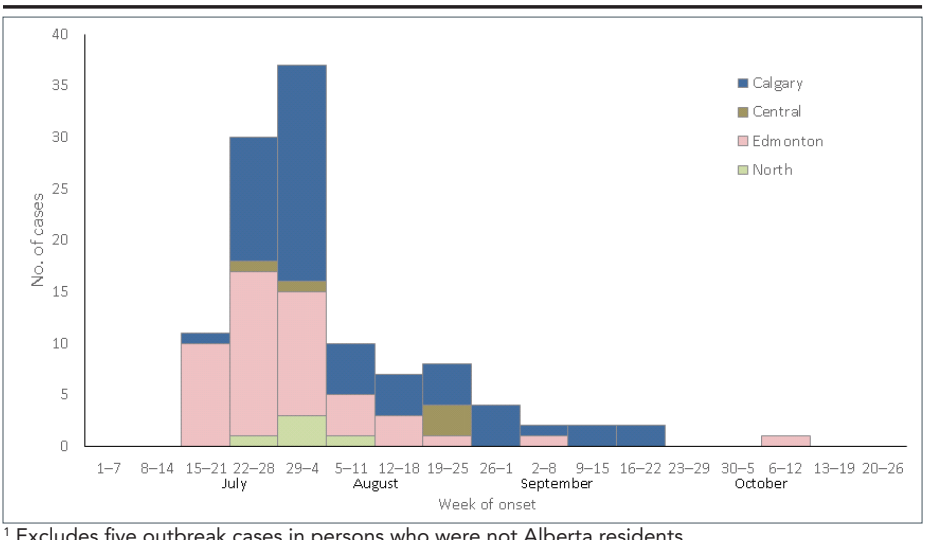

six of whom developed hemolytic uremic syndrome; no deaths were reported. The median age of patients was 23 years (range $=1-82$ years), and 76 patients $(64 \%)$ were female.

Exposure to food at Alberta Asian-style restaurants (36 facilities widely distributed across the province) was reported by 85 (74\%) of the 115 primary outbreak patients. Routine public health follow-up interviews failed to identify the source. Enhanced interviews with patients and follow-up at restaurants revealed that the exposure-specific frequency for each of seven ingredients (mung bean sprouts, beef, carrots, cucumbers, green onions, lettuce, and pork) exceeded 35\%.

\section{Environmental Investigation}

Regulatory agencies conducted inspections at 201 restaurant and food processing facilities to inform the investigation and control the outbreak. Extensive investigation of Alberta mung bean sprout supplier/distributor facilities ruled out this product as a source. A traceback investigation was initiated that focused on suppliers of the six remaining high exposure-frequency foods. No single common restaurant supplier was identified for these foods. Pork was identified as the only ingredient with a supplier network entirely within Alberta, and thus emerged as the leading hypothesized source of the outbreak. Confirmation of the complex intra-Alberta pork supplier network (Figure 2) revealed

Figure 2: Alberta pork supplier network, pork-associated E. Coli 0157:H7 outbreak — Alberta, Canada, July-October 2014, 1,3,4

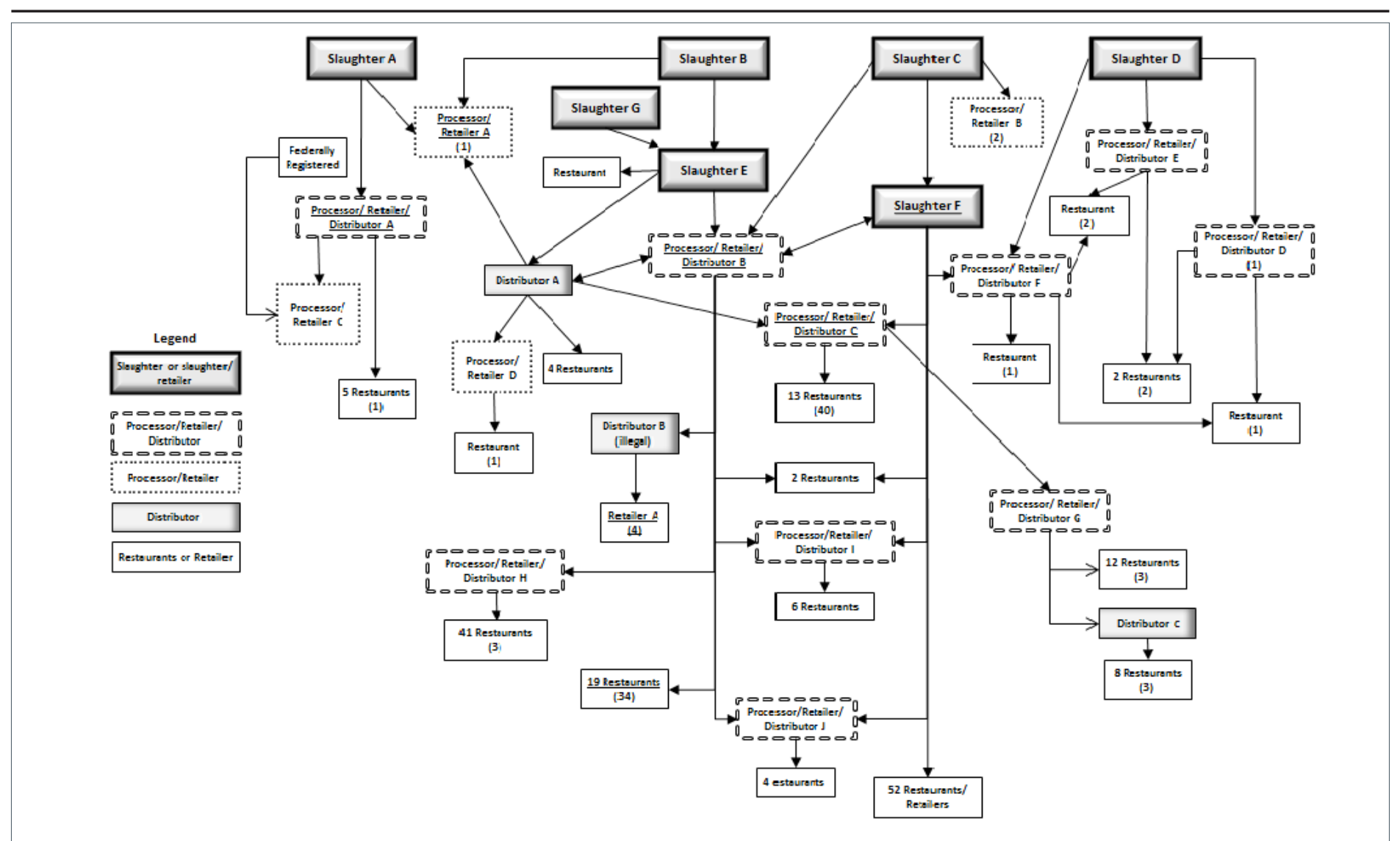

${ }^{1}$ Underlined facility $=$ E. coli $0157: H 7$-positive sample collected from the facility directly or indirectly (i.e., at home of outbreak case)

${ }^{2}$ Numbers in brackets $=$ number of outbreak cases with exposure to facility

${ }^{3}$ Some cases had multiple facility exposures

${ }^{4}$ Four secondary cases are excluded 
that exposure to food from a facility within the network was the most common identified exposure (Table 1) among primary outbreak patients $(96 / 115,83 \%)$. Most of these exposures occurred at restaurants $(81,84 \%)$. Consumption of pork was identified among $65 \%$ of outbreak patients. A total of 295 samples, including environmental surface swabs $(n=157)$, food (116), food surface swabs (13), and water (9), were collected and analyzed for the presence of E. coli O157:H7. Although a range of sample types were collected during hypothesis generation, sample collection later focused on pork and pork-production environments, as informed by the investigation. E. coli O157:H7 was identified in 18 samples, ${ }^{*}$ all of which were from pork or pork products or surface swabs in pork production facilities. Apart from two isolates from a slaughter facility, PFGE cluster patterns identified in patient isolates matched those in food and environmental sample isolates. Four outbreak cases were associated with exposure to chicken sausage products from one facility; laboratory analysis of the products identified E. coli O157:H7, detected pork, and did not detect poultry. Investigation revealed that the chicken product producer had purchased pork fraudulently labeled as chicken by an illegal distributor linked to a facility in the Alberta pork-supplier network.

Table 1: Exposure characteristics of $115^{1}$ primary cases of pork-associated E. coli 0157:H7 - Alberta, Canada, July-November, 2014

\begin{tabular}{|l|r|r|}
\hline \multicolumn{1}{|c|}{$\begin{array}{c}\text { Potential exposure } \\
\text { sites }\end{array}$} & $\begin{array}{c}\text { No. of patients } \\
\text { with exposure } \\
\text { to site }\end{array}$ & $\begin{array}{c}\text { No. of patients with } \\
\text { exposure to pork } \\
\text { (\%) }\end{array}$ \\
\hline $\begin{array}{l}\text { Asian-style } \\
\text { restaurant(s) }\end{array}$ & 81 & $48(59)$ \\
\hline Asian-style market ${ }^{2}$ & 3 & $1(33)$ \\
\hline $\begin{array}{l}\text { Sausage producer/ } \\
\text { retailer }\end{array}$ & 4 & $4(100)$ \\
\hline $\begin{array}{l}\text { Festival temporary } \\
\text { food facility }\end{array}$ & 7 & $7(100)$ \\
\hline $\begin{array}{l}\text { Meat processor/ } \\
\text { retailer }\end{array}$ & 1 & $1(100)$ \\
\hline $\begin{array}{l}\text { Asian-style } \\
\text { restaurant(s) }\end{array}$ & 4 & $4(100)$ \\
\hline $\begin{array}{l}\text { No suspect source } \\
\text { facility }\end{array}$ & 12 & $10(83)$ \\
\hline Poor historian & 3 & N/A \\
\hline Total & 115 & $75(65)$ \\
\hline
\end{tabular}

Abbreviations: N/A, not applicable; No., Number; \%, percentage

${ }^{1}$ Four secondary cases excluded

2 Facility within implicated pork supplier chain ( $96 / 115$ primary cases had this exposure)

${ }^{3}$ Facility outside implicated pork supplier chain

${ }^{4}$ After complete exposure assessment

\section{Public Health Response}

The local health department ordered four facilities, including one slaughter/retail facility, two processor/distributor/retail facilities, and one restaurant facility, to temporarily close because of the numbers of cases associated with exposure to food distributed by the facility, critical food handling violations identified, or E. coli O157:H7-positive surface swabs. The illegal pork distributor fraudulently selling pork as chicken was issued court orders to close the business and to appear for questioning. The operator failed to appear, and an arrest warrant was issued. The Canadian Food Inspection Agency issued recall notices for pork products (and chicken products containing pork) distributed by six facilities. Multiple news releases issued to local media outlets informed the public of the outbreak investigation.

Root cause analyses were conducted by food regulatory agencies at four slaughter facilities implicated in the pork supplier network. All facilities slaughtered multiple species, including cattle. Common observations included opportunities for cross-contamination related to sharing of animal pens, inadequate cleaning and sanitation of knives or equipment between carcasses, and close proximity of carcasses during slaughter activities. At the slaughter facility that was temporarily closed, inconsistent personnel hygiene practices and poor knowledge of food safety were also identified. Corrective actions related to sanitary dressing procedures, process flow, hygiene, handwashing, cleaning, and sanitation were initiated and monitored through routine inspections. Products suspected of being contaminated were removed from one facility.

Environmental Health Officers (EHOs) with the local health department conducted comprehensive assessments of pork-handling practices and other potential contributing factors at 111 restaurants (those at which patients were thought to have acquired their infection and additional, selected similar restaurants in Alberta). EHOs observed practices used by operators at baseline, surveyed them about their procedures using a standardized questionnaire, and used this information to inform intervention strategies. Only $32 \%$ of operators used validated or standardized procedures for cooking pork products; $77 \%$ used visual indicators to ascertain whether pork products were adequately cooked. Cross-contamination concerns that might have contributed to infection were identified in several restaurants; for example, $74 \%$ of facilities did not use a cleaning schedule for food equipment, and food handlers did not wash their hands between tasks in 54\% of facilities. At facilities that met food safety training requirements (82\%), trained personnel often did not have direct oversight of day-to-day food handling activities. Interventions and ongoing monitoring programs with short, intermediate, and long-term objectives were implemented at the facilities to mitigate identified problems. This phased approach included delivery of onsite food safety training by EHOs, development and distribution of educational resources in the first language of employees (printed and online), and assistance with the creation of food safety plans for properly cooking pork products. Mitigation strategies included the distribution of digital thermometers and digital timers by EHOs. During onsite training sessions, EHOs demonstrated proper handwashing and environmental surface sanitation procedures and identified other strategies operators could use to reduce the likelihood of cross-contamination. Compliance with these food safety elements was measured before and after mitigation 
strategies were carried out to help evaluate selected intervention measures.

\section{Discussion}

This outbreak represents the second largest foodborne and third largest overall E. coli O157:H7 outbreak in Canadian history, after a foodborne outbreak associated with salami produced in British Columbia in 1999 with 143 laboratory-confirmed cases (1) and a waterborne outbreak in Walkerton, Ontario in 2000 with 167 laboratory-confirmed cases (2). Strong epidemiologic evidence exists indicating that the cause of this outbreak was exposure to contaminated pork products produced and distributed in Alberta. The molecular epidemiology of the clinical and pork E. coli O157:H7 outbreak isolates is described elsewhere (3). Pork is a known, although infrequent, source of human E. coli O157 infection (4-8). Most documented outbreaks have been associated with sausage products containing pork and other meats, and the species-specific source of contamination was not confirmed. It has been reported that E. coli O157:H7 is prevalent globally at varying rates in swine, that infected swine might shed the bacteria for 2 months, and that horizontal transmission between swine and other livestock species might $\operatorname{occur}(9)$.

E. coli O157:H7-contaminated pork and pork production environments and mishandling of pork products were identified at all key points in the implicated Alberta pork distribution chain, including slaughter, processor, retail, and restaurant facilities. However, the originating source or sources of the contamination were not identified. Cross-contamination appears to be an important contributing factor in this outbreak, as evidenced by absence of known pork exposure in 35\% of outbreak cases. On the basis of the findings of this investigation, pork should be considered a potential source in public health E. coli O157:H7 investigations and prevention messaging, and pork handling and cooking practices should be carefully assessed during regulatory food facility inspections.

\section{Acknowledgments}

Brent Friesen, Kate Snedeker, Adrienne MacDonald, Alberta Health Services; Linda Chui, Jocelyne Kakulphimp, Alberta Provincial Laboratory for Public Health.

\section{References}

1. MacDonald DM, Fyfe M, Paccagnella A, Trinidad A, Louie K, Patrick D. Escherichia coli O157:H7 outbreak linked to salami, British Columbia, Canada, 1999. Epidemiol Infect 2004;132:283-9.

2. Bruce-Grey-Owen Sound Health Unit. Waterborne outbreak of gastroenteritis associated with a contaminated municipal water supply, Walkerton, Ontario, May-June 2000. Can Comm Dis Rep 2000;26(20):170-3. Available from: http:// www.collectionscanada.gc.ca/webarchives/20071214052929/ http://www.phac-aspc.gc.ca/publicat/ccdr-rmtc/00vol26/ dr2620eb.html.

3. Berenger B, Berry C, Peterson T, Fach P, Delannoy S, Li V, Tschetter L, Nadon C, Honish L, Louie M, Chui L. The utility of multiple molecular methods including whole genome sequencing as tools to differentiate Escherichia coli O157:H7 outbreaks. Euro Surveill 2015;20:pii=30073.

4. Trotz-Williams LA, Mercer NJ, Walters JM, Maki AM, Johnson RP. Pork implicated in a Shiga toxin-producing Escherichia coli O157: H7 outbreak in Ontario, Canada. Can J Public Health 2012;103:e322-6.

5. CDC. Escherichia coli O157:H7 outbreak linked to commercially distributed dry-cured salami-Washington and California, 1994. MMWR Morb Mortal Wkly Rep 1995;44:157-60.

6. Paton AW, Ratcliff RM, Doyle RM, Seymour-Murray J, Davos D, Lanser JA, Paton JC. Molecular microbiological investigation of an outbreak of hemolytic-uremic syndrome caused by dry fermented sausage contaminated with Shiga-like toxin producing Escherichia coli . J Clin Microbiol 1996;34:1622-7.

7. Williams RC, Isaacs $S$, Decou ML, Richardson EA, Buffett MC, Slinger RW, Brodsky MH, Ciebin BW, Ellis A, Hockin J. Illness outbreak associated with Escherichia coli O157: H7 in Genoa salami. E. coli O157: H7 Working Group. Can Med Assoc J 2000;162:1409-13.

8. Conedera G, Mattiazzi E, Russo F, Chiesa E, Scorzato I, Grandesso S, Bessegato A, Fioravanti A, Caprioli A. A family outbreak of Escherichia coli $\mathrm{O} 157$ haemorrhagic colitis caused by pork meat salami. Epidemiol Infect 2007;135:31114.

9. Tseng M, Fratamico PM, Manning SD, Funk JA. Shiga toxin-producing Escherichia coli in swine: the public health perspective. Anim Health Res Rev 2014;15:63-75. 